\title{
Skull and Posterior Rib Fractures with Respiratory Failure caused by Child Abuse
}

\author{
Dzulfikar Djalil Lukmanul Hakim, Elza Noviani \\ Department of Child Health Faculty of Medicine Universitas Padjadjaran \\ Dr. Hasan Sadikin General Hospital Bandung
}

\begin{abstract}
Background: Presence of multiple fractures suggests child abuse. Skull fractures rarely occurred but posterior rib fractures are commonly found and have high specificity as a radiological finding in child abuse. A respiratory failure can occur as a result of the damage to the osseous structure of the thorax that destabilizes the rib cage and impairs spontaneous breathing mechanism.

Methods: A case report of a 6-month-old boy who presented with respiratory failure, multiple bilateral parietal and occipital bone fractures, and also fractures of right rib 5-8. The patient required ventilatory support for 9 days in the Pediatric Intensive Care Unit, Dr.HasanSadikin General Hospital.

Results: The patient was on ventilatory support for 9 days, and was given antibiotics for 2 weeks. Next, the patient was referred to the High Care Unit (HCU) after the condition was stabilized, and then referred to the ward, for treatment by the Social Pediatric Division. The patient was still having issues about his foster care. Conclusions: Recognition of presence of fractures is important in early diagnosis and treatment of child abuse. [AMJ.2017;4(1):107-10]
\end{abstract}

Keywords: Child abuse, multiple fractures, respiratory failure

\section{Introduction}

Skeletal fractures are diagnosed in more than a third of children who have been investigated for physical abuse. ${ }^{1}$ They occur in infants and toddlers (under three years old) who cannot give a causal explanation about the fracture, and the incidence is around 78\%. Worlock and colleagues studied children under 12 years old and showed that $80 \%$ of all fractures from abuse are seen in children under 18 months, contrary, $85 \%$ of fractures not caused by abuse occurred in children over 5 years. The estimated population annual incidence of fracture due to abuse is 4 per 10.000 children under 18 months. ${ }^{1,2}$ Seventy four per cent of abused children had two or more fractures.1

Furthermore, chest injuries occur in $\sim 60 \%$ of polytrauma cases, hemothorax related to trauma in the United States approaches 300.000 cases per year. ${ }^{3}$

Here in, a case report of a skull fracture and rib fracture in child abuse with ventilation support in the Pediatric Intensive Care Unit (PICU) in Dr. Hasan Sadikin General Hospital, Bandung.

\section{Case}

A 6-month-old boy was brought to the emergency room with a chief complaint of dyspnea since 2 days before admission, this discomfort was not associated with cyanosis, snoring or wheezing. There was no history of choking. However, the patient's aunt recognized the history of trauma that his mother had banged the child's head against the wall, and hugged the chest too tightly. His parents were getting a divorce. Besides the mother was not aware about the bumps on the child's head.

Furthermore, the patient was admitted to PICU with an increase in breathing effort due to respiratory failure, the physical examination revealed dullness at the right intercostal 5.

The chest radiograph showed the presence

Correspondence: Dzulfikar Djalil Lukmanul Hakim, Department of Child Health, Faculty of Medicine, Universitas Padjadjaran/Dr. Hasan Sadikin General Hospital, Bandung, Indonesia, Phone: +62 222035957 Email: dzulfikar_dlh@yahoo.com 


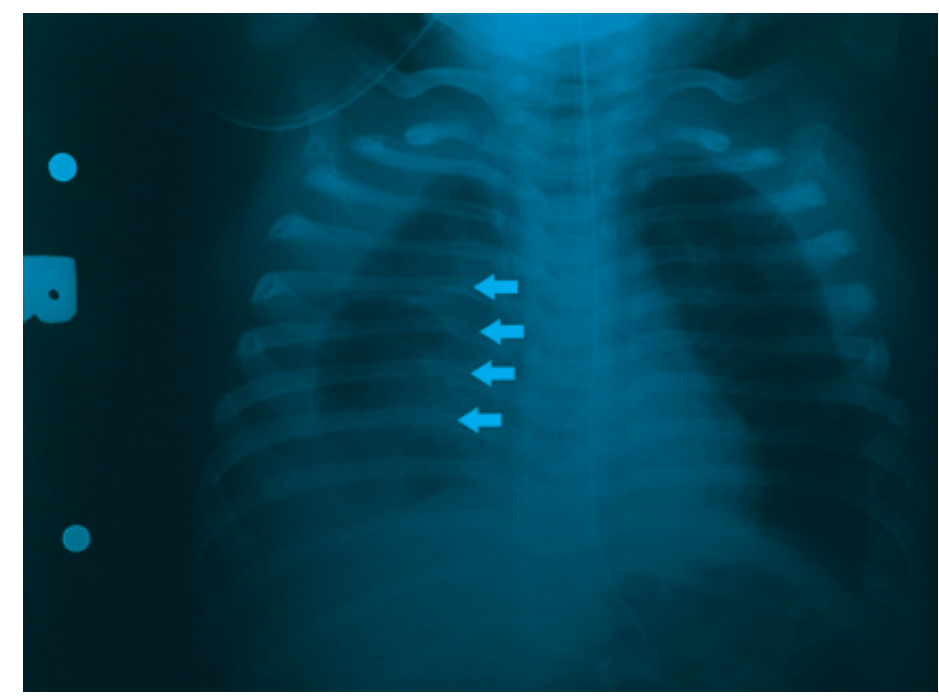

\section{Figure 1 Chest radiograph shows posterior right rib 5-8 fractures With Right Pleural Effusion}

of right rib 5-8 fractures. Schedel radiograph showed multiple fractures of bilateral parietal and occipital bones. Blood gas analysis revealed respiratory alkalosis and metabolic acidosis. Tapping on the right pleural space resulted in cloudy red fluid, which contained 500 white blood cells; pleural fluid to serum protein ratio of 0.6 ; and protein of $3 \mathrm{~g} / \mathrm{dl}$.

The patient was on ventilatory support for 9 days. At the beginning, the ventilator was at pressured controlled mode with fractional concentration of oxygen in inspired air (FiO2) $60 \%$ and gradually lowered, respiratory rate (RR)was $30 \mathrm{x} /$ minute, inspiration(I):expiration (E) $=1: 2$, and inspiratory pressure level (IPL)/ positive end expiratory pressure (PEEP) $=15 / 5$. The next day, he started to breathe spontaneously, then the settings were changed to synchronized intermittent mandatory pressure support (SIMV-PS) FiO2 40\%, RR

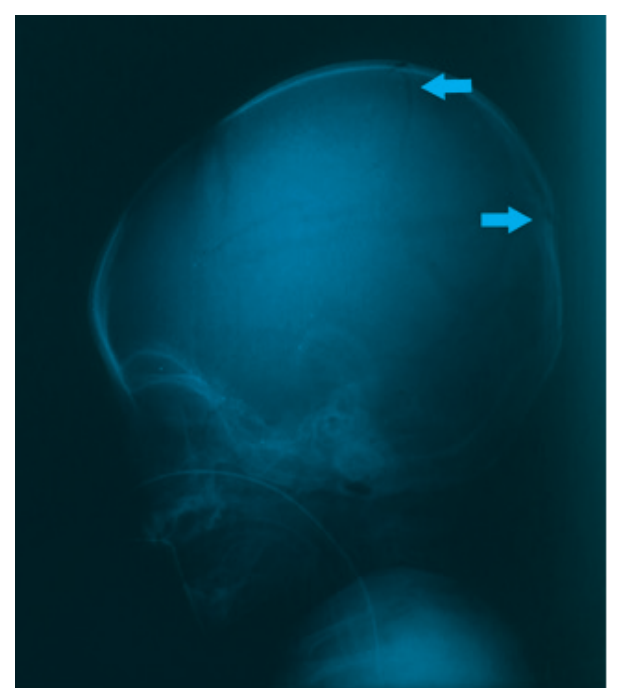

Figure 2 Schedel radiography Shows Multiple Fractures of Bilateral Parietal and Occipital Bones 
gradually decreased to $10 \mathrm{x} /$ minute, I: $\mathrm{E}=1: 2$, IPL/PEEP: 12/5. The ventilator settings was changed to pressure support mode for the next 5 days, until weaning trial can be performed in the following 2 days with minimal PS mode. The patient was given antibiotics for 2 weeks, and then referred to the High Care Unit (HCU) after his condition was stabilized, and then later referred to the ward, to be treated by the Social Pediatric Division. The patient was still having issues about his foster care. The patient was also consulted to the neurosurgeon for the multiple fractures of bilateral parietal and occipital bones, and to the thoracic surgeon for the rib fractures and they both suggested a conservative treatment.

\section{Discussion}

Skull fractures had been reported to occur more commonly in non-abusive trauma than in abusive head injury. The most common site of fracture in both abuse and non-abuse group was parietal and the most common fracture type was linear. ${ }^{1}$ In this case, the skull fractures were quite rare which occurred on both parietal sites.

Furthermore, a meta-analysis in 2008, stated rib fractures can occur at any location on the rib, they can be unilateral or bilateral. Findings on posterior rib fractures were numerous. One of the studies of the American Academy of Pediatric mentioned that most rib fractures in infants are caused by child abuse. ${ }^{4} \mathrm{~A}$ study about specificity of radiological findings discovered that posterior rib fractures have a high specificity value and the fractures are usually multiple. ${ }^{5-7}$ In this case, rib fractures occurred posteriorly and multiple.

Moreover, damage to the bony structure of the thorax by the rib fractures destabilizes the rib cage and impairs spontaneous breathing mechanics substantially, which further reduces breathing function. Direct traumatic damage to the lung, combined with a concurrent increase in vascular permeability of the lung capillaries of the injured area, leads to extravasation of protein-rich fluid, resulting in respiratory failure. Injuries of more than two ribs fractures put the patient at significant risk of complications, such as thorax instability with paradoxical motion, in severe condition, flail chest can also occur. Therapeutic aspects for this condition are to optimize ventilation, pneumatic stabilization with noninvasive positive-pressure ventilation (NIPPV) using mask, or after intubation, using invasive positive pressure ventilation (IPPV). ${ }^{8}$
In this case, the patient had respiratory failure without flail chest, and had been intubated with ventilator which was set on pressured control (PC) mode and sedation with midazolam.

From another meta-analysis in 2008, $78 \%$ studies about child abuse with fracture were performed in the United States. ${ }^{1}$ This report described a case of multiple fractures that occurred in skull (bilateral parietal and occipital) and rib fracture (right 5-8) due to child abuse, with respiratory failure and requiring ventilatory support. It is important to recognize and distinguish respiratory failure and fracture conditions between abusive and non-abusive children.

Conventional radiography has historically been and to date has continuously to be the mainstay in radiological imaging of suspected child abuse, both in identifying new cases of possible child abuse, ${ }^{9}$ but normal initial radiological imaging does not guarantee that there is no fracture. The American Association of Pediatric (AAP) recommends that a followup skeletal survey be obtained for all children $<24$ months of age who are strongly suspected to be victims of abuse. ${ }^{10}$

Additionally, retarded parents in this case report schizophrenic parents- because of their cognitive limitations were unable to care for their children. These findings point up the need for a mechanism whereby the retarded adult's right to parent and the child's right to nurturance and protection may both be preserved. Until this dilemma can be resolved, decisions to terminate parental rights in such cases should be made more quickly. ${ }^{11}$

A meta-analysis by Norman et al..$^{12}$ pointed that there is a causal relationship between child maltreatment and a range of mental and health disturbances. It is needed to establish better identification of child abuse risk and the development of effective interventions to protect children from violence. An interdisciplinary effort is needed among all the institutions sharing responsibility for child protection so that the problem of violence against children can be effectively addressed and the number and severity of cases can be reduced. ${ }^{12,13}$

\section{References}

1. Kemp AM, Dustan F, Harrison S, Morris S, Mann M, Rolfe K, et al. Patterns of skeletal fractures in child abuse: systematic review. BMJ. 2008; 337:a1518.

2. Carty MH. Fractures caused by child abuse. J Bone Joint Surg Br. 1993; 75(6):849-57. 
3. Mowery NT, Gunter OL, Collier BR, Diaz JJ Jr, Haut E, Hildreth A, et al. Practice management guidelines for management of hemothorax and occult pneumothorax. J Trauma. 2011;70(2):510-8.

4. Bulloch B, Schubert CJ, Brophy PD, Johnson $\mathrm{N}$, Reed MH, Shapiro RA. Cause and clinical characteristics of rib fractures in infants. Pediatrics. 2000;105(4):E48.

5. Kleinman PK. Diagnostic imaging in infant abuse. Am J Roentgenol. 1990;155(4):70312.

6. Robben S. Diagnostic imaging in child abuse non accidental trauma.Radiology Assistant. 2006 [cited 2014 March 1]. Available from: http://www.radiologyassistant.nl/en/ p43c63c41ef 792/diagnostic-imaging-inchild-abuse.html

7. Dwek JR. The radiographic approach to child abuse. Clin Orthop Relat Res. 2011;469(3):776-89.

8. Richter $\mathrm{T}$, Ragaller $M$. Ventilation in chest trauma. J Emerg Trauma Shock. 2011;4(2):251-9.
9. Van Rijn RR, Sieswerda-Hoogendoorn T.Educational paper: imaging child abuse: the bare bones. Eur J Pediatr. 2012;171(2):215-24.

10. Bennett BL, Chua MS, Care M, Kachelmeyer A, Mahabee-Gittens M. Retrospective review to determine the utility of follow-up skeletal surveys in child abuse evaluations when the initial skeletal survey is normal. BMC Res Notes. 2011;4:354.

11. Seagull EA, Schuerer SL. Neglected and abused children of mentally retarded parents. Child Abuse Negl. 1986;10(4):493-500.

12. Norman RE, Byambaa M, De R, Butchart A, Scott J, Vos T. The long-term health consequences of child physical abuse, emotional abuse, and neglect: a systematic review and meta-analysis. PLoS Med. 2012;9(11): e1001349.

13. Jacobi G, Dettmeyer R, Banaschak S, Brosig B, Herrmann B. Child abuse and neglect: diagnosis and management. Dtsch Arztebl Int. 2010;107(13): 231-40. 